TRABAJO DE GRADO

LOS FACTORES MOTIVACIONALES EN LA ELECCIÓN DE ÉNFASIS ORGANIZACIONAL EN PSICOLOGÍA DE UNA UNIVERSIDAD PRIVADA DE MEDELLÍN.

POR:

SILVIA NATALIA GIRALDO JARAMILLO

ASESOR:

JUAN CARLOS ESPINAL URIBE

MEDELLÍN - ANTIOQUIA

UNIVERSIDAD EAFIT

7 DE NOVIEMBRE DEL 2018 


\section{Tabla de contenido}

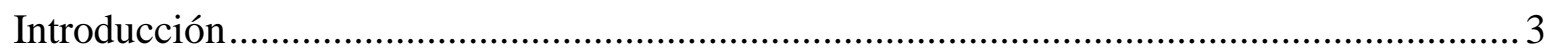

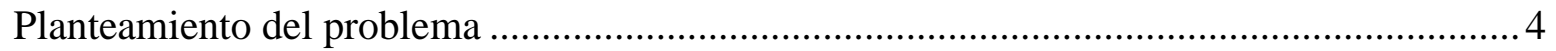

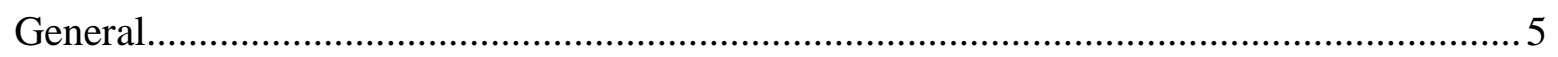

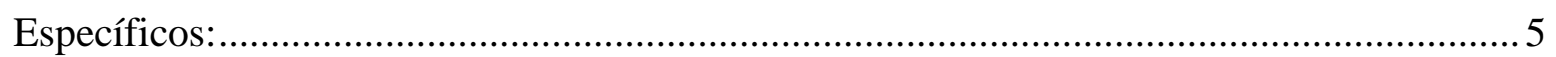

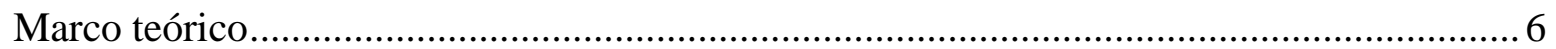

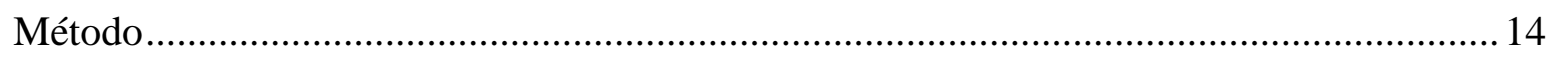

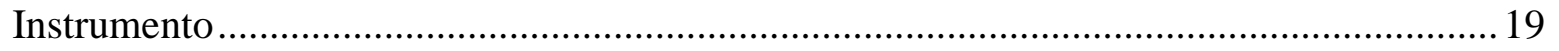

Recolección de datos y análisis de resultados .............................................................2 23

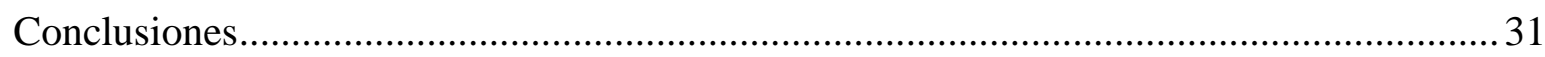

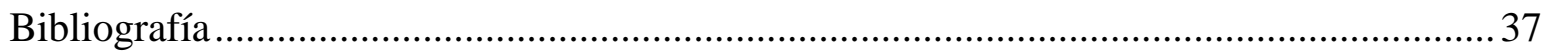




\title{
LOS FACTORES MOTIVACIONALES EN LA ELECCIÓN DE ÉNFASIS ORGANIZACIONAL EN PSICOLOGÍA DE UNA UNIVERSIDAD PRIVADA DE MEDELLÍN.
}

\author{
Por: Natalia Giraldo Jaramillo ${ }^{1}$
}

\section{Introducción}

Las investigaciones sobre factores motivacionales se han centrado en la elección de carrera en diferentes profesiones, por lo que esta investigación tiene como propósito revisar el concepto de motivación, vocación y elección de carrera en la psicología, por medio de este se desea realizar una investigación que contribuya a diferentes investigaciones hacia una búsqueda de factores motivacionales en la elección de énfasis organizacional en psicología. Igualmente por medio de esta investigación se está pensado realizar un proceso de aprendizaje que contribuya al conocimiento adquirido por medio del pregrado de psicología, con énfasis en gestión humana.

La toma de decisiones es el proceso mediante el cual un individuo tiende a hacer una elección entre una u otra acción subjetiva que afecta cierto o ciertos aspectos de su vida, es decir, que esta toma de decisiones puede o podría configurar nuestras vidas hacia cierta dirección o ciertas direcciones que conllevan consigo consecuencias y causas, las cuales el sujeto es consciente de, y por esta razón en este proyecto nos centraremos y estudiaremos en la investigación planteada, que propone concebir la motivación como un factor importante para la toma de decisiones en el que el sujeto que elija el énfasis organizacional en psicología.

Por medio de esta investigación se pretende identificar los motivos por los cuales los estudiantes de psicología y aquellos egresados del pregrado eligen este campo de acción organizacional, de igual manera se indagará sí existe una relación entre la escogencia del énfasis y no ejercer el campo clínico en la psicología, es decir, se investigará sí esta razón yace en el discurso tanto implícito como explícito del sujeto a entrevistar.

\footnotetext{
${ }^{1}$ Estudiante de noveno semestre de Psicología. Universidad EAFIT.
} 


\section{Planteamiento del problema}

Se han realizado diferentes investigaciones alrededor del concepto de la motivación en cuanto a la elección de la psicología como carrera profesional, estas investigaciones, varían en cuanto a su composición, planteando su investigación en los imaginarios alrededor del ejercicio profesional en cuanto al campo clínico, como también los motivos, expectativas e intereses que conlleva la elección tanto en la psicología clínica como en la organizacional, por otra parte otra investigación indaga acerca de las metas y los motivos que conllevan la elección de carrera universitaria, realizando un estudio comparativo entre las carreras de psicología, derecho y la biología.

El objetivo de esta investigación es explorar aquellas motivaciones alrededor de la demanda de la elección del énfasis organizacional dentro del pregrado de psicología de una universidad privada de Medellín, es decir, conocer los motivos por los que los estudiantes eligen el énfasis de gestión humana como vocación profesional dentro del mismo pregrado. Por medio de este se busca contribuir a este conjunto de investigaciones direccionadas hacia la búsqueda de los factores motivacionales que llevan a los individuos a estudiar psicología como carrera profesional, y el ejercer el énfasis organizacional dentro de dicho pregrado, para esto se espera que los resultados de la investigación aporten a los hallazgos previamente encontrados por diferentes colegas.

Se considera que es importante abordar los factores motivacionales en cuanto a su elección y posterior ejercicio laboral, ya que ésta investigación lograría complementar por medio de un abordaje diferente a las investigaciones previas que se han centrado en otras problemáticas alrededor del concepto de motivación en cuanto a la elección vocacional, además ésta investigación puede actuar como un insumo a aquellos estudiantes del pregrado de psicología que quisieran conocer acerca de los diferentes factores motivacionales que inciden en la elección de énfasis.

Por lo tanto la pregunta de esta investigación es la siguiente ¿Cuáles son los factores motivacionales en la elección de énfasis organizacional en psicología?, por medio de esta pregunta se pretende responder los diferentes factores motivacionales que afectan a 
diferentes individuos y los cuales lo llevan a escoger el énfasis de gestión humana en el pregrado de psicología.

\section{Objetivos:}

\section{General}

- Identificar los factores motivacionales en la elección que llevan a los recién graduados del pregrado o egresados de psicología de una universidad privada de Medellín a escoger el énfasis organizacional en psicología.

\section{Específicos:}

- Describir las razones o las justificaciones (explicitas o implícitas) percibidas por los sujetos, en su decisión de elegir el énfasis organizacional en psicología.

- Reconocer e identificar las motivaciones por parte del sujeto al ingresar al pregrado de psicología

- Identificar las creencias o los motivos por los que se elige con mayor frecuencia el énfasis organizacional en psicología.

- Descubrir por qué los estudiantes recién graduados o egresados deciden enfocarse en el énfasis organizacional en su qué hacer profesional. ${ }^{2}$

\footnotetext{
${ }^{2}$ Indagando por medio de ésta sí la práctica profesional influye en el campo de acción en el cuál el individuo piensa ejercer posteriormente a su graduación.
} 


\section{Marco teórico}

Algunas investigaciones referentes de la motivación y la elección de carrera infieren que los sujetos poseen diferentes motivaciones, las cuales les posibilitan la elección de carrera, y creen que es importante descubrir aquellas clases de motivaciones que conllevan a asumir, en parte, su deseo al realizar la elección. Se reconocen una tendencia en el hecho de identificar, reconocer, determinar, analizar y establecer los factores motivacionales en la elección de carrera profesional, en particular en psicología, debido a que se pretende investigar las clases o tipos de motivaciones (Gonzales, T., \& Catillo, A., 1988; Rovella, A., Sans de Uhrlandt, M., Solares, E., Delfino, D., \& Díaz, D., 2008; Rovella, A., Pitoni, D., Delfino, D., Díaz, H., \& Solares, E., 2011; “anónimo” (s.f.).; Morrillo, F., 2004), el concepto de motivación en la historia de la psicología y sus enfoques (Utria, O., 2007; Gámez, E., Marrero, H., \& Díaz, J., 2008; Naranjo, M., 2009), las motivaciones como un determinante (Lemus, M., 2014; Gámez, E., \& Marrero, H.,2003; Latiesa, M., 1987; Castro, A., \& García, M., 2015; Castro, A., \& García, M., 2000; Zúñiga, M., 2014; Gámez, E., \& Marrero, H., 2001; Rivera, M., 2012; Naigeboren, M., Carama, G., Bordier, M., Ledesma, I., \& Gil de Asar, M., 2010), el proceso motivacional (Montañés, M., 2004). ${ }^{3}$

En el presente trabajo se analizan diferentes conceptos teóricos, como lo son las motivaciones y esa tendencia dentro de esta que llevan a los individuos a inclinarse hacia cierta acción, cierto destino, diferentes alteraciones de un futuro que sólo el individuo tiene la capacidad de modificar. Posteriormente, se trabaja la elección vocacional en tanto la elección y la vocación profesional, así como también, los factores determinantes en la elección vocacional. Finalmente, se plantea la gestión humana con respecto al campo de la psicología organizacional, por lo que implicaría el rol que el psicólogo asume dentro de una organización.

El concepto de motivación es un constructo teórico-hipotético que designa un proceso mental complejo que causa la conducta, la motivación interviene en múltiples variables,

\footnotetext{
${ }^{3}$ Este apartado se construye a partir del trabajo de grado de Natalia Orduz Gómez, "Imaginarios alrededor de la elección del campo ocupacional de la psicología clínica como vocación profesional en un grupo de graduados de psicología de una universidad privada de Medellín".
} 
tanto biológicas como adquiridas, que influyen en la acción, direccionalidad, intensidad y coordinación del comportamiento llevado a lograr aquella meta propuesta por el mismo individuo.

La motivación es una de las principales claves explicativas que busca informar el porqué de nuestras acciones. Esta motivación comienza por medio de la activación (inicio de acción), en segunda parte esta se dirigirá a un objetivo (dirección de dicha acción), y por último, el tercer paso es el de mantenimiento, que hace que esta acción y esta dirección se mantengan en alcanzar el objetivo planteado por el individuo. (Naranjo Pereira, 2009)

A lo largo de la historia, autores han definido la motivación de diferentes maneras, en donde la gran mayoría han sido asignadas para explicar las causas del comportamiento y conducta por parte de los individuos, dichos comportamientos fueron explicados por medio de procesos psicológicos básicos, vinculados con la acción de la persona en cuestión, dicha acción es asociada entre lo causal y el efecto, en donde la motivación sería hallada como el causal de dicha acción y el efecto de esta sería la conducta consecuente de dicho motivo para proceder a realizar cierta actividad propuesta por el individuo. Asimismo la motivación según otros autores, no es un hecho de la conducta, es decir, éste no es determinante en cuanto un individuo actúa, para este actuar entran en juego diferentes factores; la motivación sería entendida como una tendencia ${ }^{4}$ (Real Academia Española) que tiene el ser humano. De esta manera, la motivación se entiende como la compleja integración de procesos psíquicos que regulan el comportamiento, pues éste determina la intensidad y el sentido de dicho comportamiento. (Naranjo Pereira, 2009)

En particular la historia de la motivación comienza entre la década de 1920 hasta mediados de 1960, comenzando por medio de una investigación experimental, sobre la conducta motora, el instinto ${ }^{5}$ (Real Academia Española) y el impulso ${ }^{6}$ (Real Academia Española),

\footnotetext{
${ }^{4}$ Tendencia: Según la Real Academia Española, tendencia es aquella propensión o inclinación que tienen las personas para realizar determinados fines, es esa fuerza que se orienta a determinada dirección.

${ }^{5}$ Instinto: la Real Academia Española define el instinto como aquel conjunto de pautas de reacción que, en los animales, contribuyen a la conservación de la vida del individuo y de la especie, es decir, son aquellos impulsos que a partir de una situación desata en el individuo aquel "instinto reproductor" que hace que el individuo reaccione de cierta manera. Este es innato.

${ }^{6}$ El impulso es definido según la RAE (Real Academia Española) como el deseo o motivo afectivo que induce a realizar una acción de manera súbita, es decir, sin reflexionar. Actuar sin pensar primero.
} 
esta investigación se hizo con la finalidad de descubrir qué conduce a un organismo a restaurar su estado de equilibrio, realizando esto por medio de factores externos, como lo son los refuerzos.

A mediados de los años sesenta Atkinson señala que la motivación se determina por el valor que la persona le ha otorgado a la meta y las expectativas que este tiene para lograrla. A partir de los años setenta la tendencia está marcada por teorías cognitivas. Diversos estudios se refieren a aspectos como el papel que juega la atribución causal, percepción de competencia, percepción de control, capacidad y autoeficacia que posee el individuo. Las teorías sobre motivación de base cognitiva tienen un gran valor para la educación ya que estas facilitan el entendimiento de la conducta y el rendimiento escolar y permiten determinar estrategias para reforzar la motivación del estudiante. (Naranjo Pereira, 2009, p. 4)

El concepto de motivación es un aspecto enorme que se encuentra en diversas áreas de la vida, entre ellas la educativa y la laboral, esta orienta y se conforma en un elemento central que conduce al sujeto a un objetivo propuesto, dirigiendo sus energías en realizar este objetivo, con el fin de satisfacer sus propios propósitos. Según Santrock (2002), la motivación es ese "conjunto de razones por las que las personas se comportan de la manera que lo hacen, siendo este comportamiento vigoroso, dirigido y sostenido" (Naranjo Pereira, 2009, p. 153), según este mismo autor, existen tres perspectivas fundamentales respecto a la motivación, estas son: la conductista, esta se enfoca en el papel que tienen las recompensas en la motivación, por otra parte la humanista, se centra en las capacidades del ser humano para desarrollarse en la medida del tiempo y la cognitiva es aquella que se enfatiza en el poder del pensamiento. Dentro de la perspectiva conductual se señala que tanto las recompensas como los castigos tienen un papel protagónico en este espectro motivacional, las recompensas son aquellos eventos positivos o negativos que puede llevar a que una persona a que se comporta de cierta manera.

En algunas ocasiones las personas, con el objetivo de obtener un beneficio en específico, se comportan de forma diferente a la habitual, por medio de estos comportamientos buscan evitar así aquellas conductas que los pueden llevar a un daño, es decir, que las personas se comportan de cierta manera con el fin de obtener una retribución por su comportamiento, o 
de igual manera, buscan evitar aquello que a su parecer sea desagradable, por lo que quiere evitar u omitir dicha acción que lo lleve a esto. Estos comportamientos se realizan con el fin de satisfacer aquellas necesidades de la persona. (Naranjo Pereira, 2009, p. 4)

Otra definición de la motivación es, aquella fuerza que despierta, mantiene y fortalece la intensidad del comportamiento del ser humano, éstos son manifestados por medio de deseos, sentimientos, emociones, aspiraciones y metas que definen el existir de dicha motivación. No solamente ésta fuerza se encuentra dirigida hacia propósitos de cada ser humano, la persona de igual manera define la intensidad de acuerdo el propósito es satisfecho. Es importante resaltar que el ser humano constantemente cambia, por ende este no es estático, por lo que se puede modificar la dirección y el grado de intensidad para llegar a la meta pactada decidida por el individuo. (González Serra, 2008)

Precisamente por el hecho que el ser humano se encuentre en un constante cambio, a nivel biológico, éste proceso se caracteriza por su constante auto-renovación (González Serra, 2008, pág. 122), por lo que a lo largo de su vida supone las dificultades con las que el concepto de motivación ha tenido que enfrentarse, ya que, se entiende la motivación como un proceso cambiante y dinámico. (Utria, 2007, pág. 57) A esta dinámica se le debe ser sumada el factor social, al cual el sujeto no es externo, este está inmerso en él, reflejándose y conteniéndose recíprocamente, éstos determinantes, sociales y culturares, constituyen realidades en sí mismas, constituyendo leyes propias, creencias, formas de actuar entre otros comportamientos, éstas a su vez actúan a través y en dependencia de dicha influencia. (González Serra, 2008, pág. 175) Por lo que la motivación es un determinante directamente causado por estos factores sociales y además por la actividad interna de cada sujeto.

Asimismo este proceso es atravesado e influenciado por la voluntad de cada persona, siendo la voluntad definida como un mecanismo mental que permite cambiar el comportamiento. (Utria, 2007, pág. 63), ésta voluntad conduce en un alto grado los sentimientos propios, llevándolos al resultado ya previsto por el sujeto en cuestión. Lo anterior puede ser entendido como la inteligencia emocional, según Daniel Goleman, la inteligencia emocional es esa capacidad que poseemos los seres humanos para reconocer y manejar nuestros sentimientos, de igual forma, nos motiva y monitorea nuestras relaciones, ésta teoría está basada en la cognición, personalidad, motivación, emoción e inteligencia, 
por lo que incluye tanto procesos psicológicos cognitivos como los no cognitivos. (Federación de Enseñanza de CC. OO. de Andalucía , 2011) Por medio de dicha inteligencia emocional, el individuo está capacitado de regularse emocionalmente, pasando por un proceso inicial de monitorización (percatarse de emoción o sentimiento), evaluación (valorar por qué esta emoción le afecta) y por último se realiza una puesta en acción para cambiar nuestro estado de ánimo. Una forma de regulación de estado de ánimo propio, se da por medio de su interacción social, siendo estos amigos, compañeros de trabajo, equipo de trabajo, familia etc..., el hecho de asociarse con otros seres humanos supone éxito sin llevar a una amenaza, llevando así a un afecto positivo, al contrario de asociarse con personas consideradas exitosas en áreas socialmente importantes, supone sentimientos negativos como lo es, por ejemplo, la envidia. En general los individuos intentan mantener estados de ánimo positivos y evitar los negativos buscando información que busque mantener dicha visión positiva de sí mismo, es un proceso encaminado al mantenimiento, reparación e incluso prolongación de los estados emocionales placenteros con el fin de atenuar las experiencias desagradables. (Amy Melgarejo, 2015, pág. 16)

Sí el individuo encuentra un propósito que éste desee alcanzar y halla gusto y placer en alcanzarlo, este encontrará el éxito. Por lo que el individuo debe descubrir y consecuentemente elegir aquello que le dé razones y propósitos para alcanzar por medio de lo propuesto el éxito.

Por lo que la motivación organizacional se puede definir como aquella motivación que utiliza incentivos y estímulos para atraer el deseo de los individuos con el fin de que éstos los lleven a cabo. Un individuo se siente motivado cuando este percibe un estímulo que lo obliga a realizar un esfuerzo ${ }^{7}$ y orientar sus fuerzas para satisfacer dicho deseo. Alcanzar esta meta supone un sentimiento de satisfacción para el individuo al haber cumplido la meta, esfuerzo, deseo entre otros. (Peña Estrada, 2015, p. 12) La motivación juega un rol importante en la gestión de personas, para que un individuo realice una tarea éste debe superar tres requisitos: que el individuo posea los medios para realizarlos, poseer tanto

\footnotetext{
${ }^{7}$ el Esfuerzo es aquella fuerza que el individuo utiliza para alcanzar un fin determinado, ésta fuerza puede ser tanto física o moral.
} 
habilidades y aptitudes aptas para realizar la tarea y por último que éste motivado a realizar la acción.

Por su parte, la motivación laboral se define como aquella voluntad que poseen los individuos en realizar altos niveles de esfuerzo con el fin de obtener metas organizacionales, condicionadas así, por la satisfacción de alguna necesidad individual. La motivación laboral es considerada como el proceso micro-estudiado en mayor profundidad de la psicología del trabajo, realizándose múltiples investigaciones con el fin de identificar la clave definitiva para la motivación. (Peña Estrada, 2015)

Uno de los principales hallazgos del autor Frederick Herzberg fueron sus investigaciones que tenían como meta darle explicación a las causas de la motivación y la satisfacción laboral, del cual Herzberg asegura que no por el hecho de eliminar las fuentes de sufrimiento de los individuos, significa automáticamente que éste produce placer en las personas, Herzberg afirma que este llega a un punto neutro, ya que el placer es el resultado de diferentes factores que ejercen en el sujeto. De igual manera en el ámbito laboral sucede lo mismo, al retirar las fuentes de insatisfacción en los empleados no necesariamente se asegura una satisfacción absoluta en el lugar de trabajo. (Manso Pinto, 2002, pág. 80)

En 1959, Herzberg publica su trabajo "Motivation at Work" (Motivación en el trabajo) en donde expone tanto sus propias investigaciones respecto al tema, como también el conjunto de investigaciones de sus colaboradores. En este informe expuso formalmente su Teoría de Motivación - Higiene, esta investigación surge a partir de una investigación realizada en un grupo de ingenieros y contadores, los cuales respondieron preguntas relacionadas con situaciones como: recordar un momento en donde dicha persona se haya sentido a gusto en el trabajo, indagando así en el contexto de dicha memoria, en donde sucedió, como lo hizo sentir, porqué guarda un lugar especial en la persona entre otros, también se les preguntó lo totalmente opuesto, relatar un momento en donde se hayan sentido insatisfechos con su trabajos. A partir de las respuestas de los ingenieros, Herzberg y sus colaboradores concluyen que la motivación en ambientes laborales es influenciada por factores tanto independientes como específicos, influyendo de diferentes maneras en variados individuos. En una instancia los sentimientos negativos o de insatisfacción de los empleados eran atribuidos al contexto de sus puestos de trabajo, a esta conclusión Herzberg lo denomina 
Factores de Higiene, ya que actuaban de manera pareja a los principios de la higiene médica: eliminando o previniendo los peligros a la salud del individuo, estos factores abarcan la supervisión, relaciones interpersonales, prestaciones, seguridad en el trabajo, también como lo son políticas y prácticas administrativas de la empresa. Según Herzberg dichos factores mencionados no están presentes o se aplican incorrectamente en la organización, por lo que no permiten que el empleado logre una satisfacción esperada ni para el criterio del propio sujeto, ni para la organización. (Manso Pinto, 2002, pág. 81)

De otra forma Herzberg denominó a aquellos factores que se asociaban con las experiencia satisfactorias que los empleados experimentan, (las cuales también tendían a atribuir a los contenidos del mismo puesto de trabajo), como "Factores Motivadores" en estos factores se hallaron aspectos positivos como los son la realización personal que se obtiene en el puesto de trabajo, reconocimiento del desempeño, los factores trascendentes a la tarea que se realiza, satisfacción por la responsabilidad impuesta por parte de la gerencia y las oportunidades de avance laboral entre otros. Herzberg asegura que sí estos factores se encuentran presentes en el puesto de trabajo, favorecen directamente al incremento del nivel de motivación, estimulando un desempeño superior. De acuerdo con lo anterior, Herzberg, establece que la satisfacción y la insatisfacción son conceptos independientes e diferentes, por ende concluye que aumentar los incentivos, mejorar las relaciones humanas y el establecimiento de condiciones adecuadas de trabajo no generan una mayor satisfacción, estas sólo actúan previniendo o eliminando la insatisfacción en el lugar de trabajo. (Manso Pinto, 2002)

La elección se puede entender, como el hecho de decidirse por una opción entre las disponibles. Elegir es condición de tener libertad para poderlo hacer. Esta libertad según el filósofo Amartya Sen se define como aquel conjunto de oportunidades que se presentan a una persona para desarrollar sus capacidades en uno u otro estilo de vida (Segú, 2015).

Lo que conlleva a tratar de definir la vocación profesional y los factores determinantes en la elección vocacional, la vocación se entiende como la vivencia subjetiva que la persona experimenta cuando elige una profesión y que por ende corresponde a una inclinación con respecto a un desempeño profesional determinado por las propias las aspiraciones, rasgos personales, cualidades, competencias y valores de cada sujeto (Segú, 2015) 
La vocación se puede interpretar como un indicador objetivo de la inclinación hacia una profesión que coincide con los rasgos personales, capacidades, competencias y valores que posee quien la elige, de igual forma, ésta también se puede interpretar como aquel indicador subjetivo que se genera cada una de las personas, siendo estos factores de gusto, pasión, afición y satisfacción. El sentir esta vocación en el lugar de trabajo, beneficia al desempeño profesional, ya que la persona posee tanto un bienestar pero también siente gratificación al poder trabajar en algo que realmente le apasiona y disfruta. Es decir que la vocación profesional es aquella acción que le permite a la persona aprender a elegir entre las alternativas que se le presenten, dentro de su propio proyecto de vida, estas se eligen de acuerdo a la afinidad que tiene la persona con aquella particular carrera (dentro de esta se encontrarían variables como lo son la inversión de tiempo, costo, vigencia de carrera y mercado en el cual se encuentre). (Castañeda Lemus, 2004, p. 35)

La vocación es ese llamado a cumplir una necesidad, pero no necesariamente implica el cumplimiento de esta, debido a que las tendencias vocacionales orientan al ser humano hacia valores socioculturales al cual la persona se encuentra impregnada. El factor representativo lo constituye el objeto o la actividad que está dirigida hacia la vocación que orienta al sujeto. (Anónimo, Vocación)

En lo cual, la motivación subjetiva (o intrínseca) hace referencia a "aquel estado subjetivo que promueve y mantiene la realización de una actividad por la actividad misma, sin que medie ninguna finalidad o recompensa externa. Dicho de otro modo, la actividad se convierte en una finalidad o en un motivo en sí misma, y no un medio para otra finalidad diferente." ("anónimo (s.f.)). Es decir, el deseo del sujeto es "suficiente" para ser tomado como un motivador al momento de hacer una actividad o de tomar una decisión y en este caso al hacer una elección.

Por ejemplo para el individuo inmerso en el ámbito laboral, la organización debe tener en cuenta qué motivación predomina a partir del perfil, en cierto individuos es bueno tener en cuenta que éstas motivaciones pueden incrementar sacando el máximo provecho de esta fuerza motivacional mediante feedbacks continuos como lo son los refuerzos positivos en cuanto a la buena ejecución de variadas actividades. Por lo que es necesario que la Psicología Organizacional intervenga por medio de estas acciones en las empresas. 
La psicología organizacional es esa rama de la psicología que se encuentra enfocada en el trabajo y afines, busca que la motivación, satisfacción, seguridad y productividad se mantenga y/o incremente dentro de los trabajadores inmersos en dicha organización. De igual manera atiende la operación y el diseño de las organizaciones, buscando perfeccionar la relación que existe entre los trabajadores y su puesto de trabajo. Sus funciones se encuentran en el área administrativa de recursos humanos, colaborando así en la ubicación de puestos de trabajo de acuerdo con el perfil solicitado por la misma empresa, este requerimiento define el rol que el aspirante debe poseer, de igual manera trata de optimizar el modelo de incentivos para los empleados, potenciar la formación de los profesionales, poniendo en marcha programas para el desarrollo de habilidades tanto de los subordinados como el de los directivos de la empresa, mejorando así la comunicación entre estas. El campo de acción de dichos psicólogos es amplio, estas podrían ser empresas públicas o privadas, en áreas industriales, comercial y en toda situación laboral. Por lo general se encontrará en el área de Recursos Humanos, ésta de igual manera puede llamarse de diversas formas en diferentes organizaciones como lo son el área de Desarrollo Humano, Gestión Humana etc..., ocupando puestos como lo son el de gerente de recursos humanos, gerente de desarrollo, jefe de selección de personal, analista de desarrollo humano, analista de personal entre otras. (Castañeda Lemus, 2004, p. 33)

Aquellas personas graduadas de psicología con el énfasis de gestión humana, tendrán competencias necesarias desempeñarse en el ámbito laboral en las empresas, por medio de una formación humanística y valores en Gestión Humana, buscando la productividad de la empresa y también la calidad de vida del personal que laboran en ella, desarrollando así el talento humano que se encuentra dentro de la empresa. La empresa esperará que estos psicólogos transformen a las organizaciones más humanas, éticas y responsables. (Castañeda Lemus, 2004, p. 34)

\section{Método}

Se considera la hermenéutica como una teoría general de la interpretación, teniendo como dedicación la indagación atenta tanto del autor como de su obra textual, es decir, que la 
hermenéutica se podría entender como aquella actividad de reflexión que permite al mundo la captación plena de su sentido. (Arráez, Calles, \& Moreno de Tovar, 2006, pp. 173 - 174)

Por lo que es necesario emprender la indagación a partir de ese hilo conductor propuesto desde las palabras, pues el lenguaje y las palabras constituyen la única expresión absoluta e inteligible de la interioridad del otro individuo, es esta palabra del otro la que nos acerca a aquel entendimiento por medio de la hermenéutica. El término hermenéutica corresponde al arte de interpretar los textos, y la interpretación se identifica como la comprensión de todo texto (u discurso) que no sea inmediatamente evidente entre el interlocutor y el recepto, siendo este un discurso, un texto, una explicación etc., el hermeneuta se dedica entonces a interpretar el sentido de los mensajes haciendo que su comprensión sea posible, evitando malentendidos entre los agentes implicados. (Arráez, Calles, \& Moreno de Tovar, 2006, pp. 172 - 173)

Según Gadamer, la hermenéutica es el arte de llegar a un entendimiento de algo o con alguien, llegar al entendimiento de nuestras situaciones practicas es carácter de conversación. A diferencia, Friedrich Schleiermacher sostiene que la comprensión no es algo mecánico, ya que este depende del talento para el lenguaje y el talento para el conocimiento de las personas individuales. Con el fin de comprender al otro, es necesario observar cómo los interlocutores expresan sus interpretaciones. En el rol psicológico es importante prestar atención a todos los signos expresados por el otro, por lo que se construye diferentes discursos expresados tanto conscientes como inconscientemente por el otro, por medio de esto se llega a una comprensión global de aquello transmitido. (Orange, 2003, p. 10)

Dilthey fue aquel quien le adjudicó a la hermenéutica la misión de interpretar las palabras, escritos, textos etc., afirmando que para realizar estas interpretaciones es necesario hacer una buena observación e interpretación de eventos existenciales, manifestando que esto se podría realizar por medio de estudios lingüísticos, filosóficos, contextuales entre otros, por esto Dilthey, sugirió una técnica fundamentada en el "círculo hermenéutico", siendo este el "movimiento del pensamiento que va del todo a las partes y de las partes al todo, de manera que en cada movimiento aumente el nivel de comprensión: las partes reciben significado del otro y el todo adquiere sentido de las partes" (Arráez, Calles, \& Moreno de Tovar, 
2006, p. 176), siendo este un proceso que busca encontrar el sentido del texto contrastado en la experiencia humana.

El proceso de apropiación comprensiva según Heidegger se ve atravesado por dos momentos: el primero es aquella proyección anticipatoria, la cual es intuitiva, aquello por comprender se comprende y el segundo, es un previo e inevitable "enraizamiento de la facticidad y la historia", para esto Heidegger utiliza como ejemplo la adecuada utilización de un martillo, afirmando que la experiencia es la que determina el acceso a la comprensión de cómo se debe utilizar y para qué sirve un martillo, por lo que en la mayoría de los casos es de mayor facilidad entender por medio de la experiencia personal en cuanto el otro busca que se entienda cierto objeto, discurso, ejercicio entre otros.

"La tarea metodológica del intérprete, por lo tanto, no consiste en sumergirse completamente en su objetivo, sino en encontrar maneras viables de interacción entre su propio horizonte y aquel del cual el texto es portador", es decir, que con el objetivo de entender al otro, la persona debe encontrar diferentes maneras para su interpretación, utilizando el diálogo como una herramienta para conocer la posición del otro y lo que este busca poner en juego. (Maldonado Oñate, 2016, p. 8)

Por lo que este método hermenéutico se utilizará se tiene planteado utilizar la entrevista a profundidad como metodología, la cual tiene como objetivo adentrarse en el mundo del otro, interpretado su discurso en cuanto este es relevante a la investigación.

A continuación se realiza un recorrido a través de la experiencia académica a lo largo de la historia, comenzando con la creación y evolución de la Universidad como tal, como ésta surge, cómo cambia ésta la cultura en épocas antiguas, el año en qué esta llega por primera vez a América Latina, aquella población que ingresa a las Universidades etc..., posteriormente se hace un recorrido histórico a través de la historia de la Universidad EAFIT, el pregrado de psicología en dicha institución y por último se especifica cómo es el proceso de práctica profesional tanto en un sentido global como el proceso que se lleva a cabo en la Universidad EAFIT.

La Universidad, como institución, comienza su historia desde Europa medieval, tendiendo antecedentes en culturas como lo son la griega, romana y arábica. Las primeras 
instituciones con una organización formal nacieron formalmente en Europa Occidental, Bolonia y París, representando así los prototipos de universidades medievales, tanto por su antigüedad y su forma de organización. Estas instituciones evolucionaron paulatinamente por lo que para el siglo XII estaban constituidas como tales. Las universidades llegan a América Latina, a partir de 1950. En estas instituciones sus estudiantes (en un principio pocos) se sumergen en un mundo donde se accedía a la enseñanza superior impartida por unos pocos establecimientos bien identificados dentro de la sociedad, en la actualidad, éstas instituciones se encuentran esparcidas por todos los países conformadas por jóvenes, adultos, niños, adultos mayores, asisten a clases a una variedad de carreras que satisfacen sus ganas de estudiar. (González Cuevas)

La Universidad hace alusión a una institución de enseñanza superior que comprende diversas facultades, centros de investigación, escuelas, profesionales, departamentos entre otros, y ésta otorga a sus académicos al culminar el título de profesional. Desde tiempos históricos la sociedad ha confiado y respaldado a las universidades como instituciones formadores de profesionales, contribuyendo así a la sociedad, formando individuos integrados con los saberes de dicha carrera universitaria, que servirán para ocupar cargos en la sociedad. (Navarrete Cazales, La universidad como espacio de Formación profesional y constructora de identidades., 2015)

El 17 de Agosto del año 1960 se realizó la primera clase de la Escuela de Administración y Finanzas (EAF) encargado por el docente norteamericano Bernard J. Hargadon JR. Los primeros cursos se dictaron en una casa alquilada, en donde se escogieron 59 estudiantes de 200 aspirantes para la carrera de Administración de Negocios. En el año 1961 se creó el Instituto Tecnológico (IT), el cual aportó económicamente y en infraestructura a la fundación de Whirlpool y del programa Tools for Freedom. Por lo que en 1962, se fundó como tal la Universidad EAFIT (Escuela de Administración, Finanzas e Instituto Tecnológico) ubicándose en el sector de La Aguacatala, al sur de Medellín, Colombia. (EAFIT) 
En la actualidad, la Universidad, celebra su Acreditación de Alta Calidad ${ }^{8}$ (Ministerio de Educación Nacional) por parte del Ministerio de Educación Nacional. El aval es hasta 2026.

El pregrado de psicología en la Universidad EAFIT asegura que: "En EAFIT, la psicología no se limite únicamente a la formación técnica del estudiante. Por eso, se considera que un profesional eafitense debe adquirir competencias para la comprensión y el análisis de las realidades humanas. Escuchar, analizar e intervenir se constituyen en medios para fomentar una actitud analítica y pluralista del ser humano. “ (EAFIT) Como objetivos tiene: formar psicólogos desde una perspectiva analítica-comprensiva, con competencias en investigación, asesoría y consultoría organizacional, capaces de responder a los retos de las instituciones (empresariales, educativas, deportivas, de la salud, investigativas, jurídicas, social comunitarias, entidades públicas o privadas, ONG's, entre otros) que pueden acercase a la comprensión de los fenómenos sociales, por medio del análisis de las relaciones entre trabajo, hombre y organización. Formar psicólogos con conocimientos en investigación y aplicación de teorías y técnicas propias de la psicología, propendiendo por la incorporación de competencias que permitan escuchar, analizar e intervenir. Profundizar en el conocimiento y el desarrollo de habilidades y destrezas en una actividad específica del ejercicio profesional de la psicología, como por ejemplo, la investigación, al acercarse a la comprensión y aplicación de los métodos de investigación en estudios relacionados con el comportamiento del ser humano, además del diálogo con diversos campos profesionales. (EAFIT)

La práctica profesional es aquel punto definitivo en el que el estudiante entra, por un semestre a una organización, con el fin de comprender cómo es el ejercicio de la profesión

\footnotetext{
${ }^{8}$ Según el Ministerio de Educación Nacional la acreditación es el reconocimiento por parte del Estado de la calidad de instituciones de educación superior y de programas académicos, es una ocasión para valorar la formación que se imparte con la que se reconoce como deseable en relación a su naturaleza y carácter, y la propia área de conocimiento. El proceso de acreditación se desarrolla a través de la evaluación de calidad realizada por la institución misma (autoevaluación), por pares académicos externos (heteroevaluación) y por el Consejo Nacional de Acreditación (evaluación final). El proceso termina con el reconocimiento público de la calidad por parte del Ministerio de Educación Nacional.
} 
la cual escogió. Para dar este paso el estudiante debe de cumplir ciertos créditos ${ }^{9}$ (Ministerio de Educación Nacional) para embarcarse en esta nueva aventura laboral. Al ser vinculado a una empresa, el estudiante será referido como el "aprendiz" o "practicante" del área en la cual su carrera profesional tiene afinidades, y estará laborando bajo un contrato de aprendizaje (en donde su remuneración será en salario mínimo mensual vigente). Según el profesor Javier Correa Correa, coordinador de prácticas de la Universidad Central, el objetivo de la práctica profesional es que "el estudiante se enfrente con la realidad, que aprenda a envolverse profesionalmente, la idea es que no solo trabaje o produzca para que lo vea el profesor sino que se confronte con otras voces distintas a las de la Universidad". Igualmente, el Viceministerio de Educación Superior, aclara que la práctica es un requisito para culminar los estudios y consiguientemente obtener el título, por lo que se encuentra establecida en el plan de estudios de cada programa académico. Por lo general el período de práctica se encuentra entre los últimos semestres del programa académico. (Cuervo)

Para EAFIT, las prácticas profesionales se encuentran precedidas del semestre de prepráctica, en donde el estudiante debe presentarse a diferentes actividades propiciadas por la Universidad con el fin de que éste conozca los deberes y derechos a los cuales estará aferrado en cuanto éste se encuentre en la práctica (conocer que puede o no hacer en la organización, presentarse a asesorías de práctica con el mentor asignado entre otros).

\section{Instrumento}

El instrumento que se utiliza para esta investigación será la "entrevista a profundidad" la cual tiene como intencionalidad adentrarse en la vida del otro, comprender, penetrar y detallar en lo trascendente, conocer y descifrar los gustos, miedos, satisfacciones, angustias y alegrías que el otro permite (consciente e inconscientemente) que el entrevistador rescate según su propia relevancia, este puede ser descifrado por medio de la forma en que el otro realiza su discurso, peculiaridades en su hablar, los gestos entre otros. La entrevista en profundidad sigue el modelo de conversación entre iguales, son reuniones orientadas hacia

\footnotetext{
${ }^{9}$ Un Crédito Académico es la unidad que mide el tiempo estimado de la actividad académica de cada estudiante en función de las competencias profesionales y académicas que se espera que el programa desarrolle. El Crédito Académico equivale a 48 horas totales de trabajo del estudiante.
} 
la comprensión de las perspectivas que tienen los informantes respecto de sus experiencias, situaciones y respecto a su vida en general, expresados en las propias palabras del entrevistado. (Robles, Septiembre - Diciembre, 2011, p. 40)

Para Cicourel, la entrevista a profundidad consiste en adentrarse al mundo privador y personal de extraños con la finalidad de obtener información acerca de su vida. (Robles, Septiembre - Diciembre, 2011, p. 40)

Para esta técnica, el entrevistador es un instrumento más de análisis, en donde éste explora, detalla y capta por medio de preguntas, la información más relevante para los intereses de la investigación que se llevará acabo. Es tarea del entrevistador que la persona la cual será entrevista se encuentre en un estado de plenitud en el cual se pueda expresar libremente. (Robles, Septiembre - Diciembre, 2011, p. 40) El entrevistador es aquella persona encargada de llevar a cabo la entrevista, es decir, éste es que la debe planificar, plantear las preguntas, escuchar y registrar las respuestas de las personas entrevistadas. La entrevista se convierte en una conversación que persigue un propósito, éste propósito depende del mismo entrevistador, esta conversación tiene el objetivo de obtener información sobre aspectos específicos en torno a un tema planteado por el mismo entrevistador. (IBERTIC)

Por medio de esta investigación se busca conocer el por qué el énfasis organizacional en psicología es elegido por los estudiantes y egresados de este pregrado, sea esta escogencia al principio del pregrado o posterior a la práctica profesional, de igual manera se buscará indagar, investigar y conocer por qué este campo tiene tanta fuerza dentro de estos alumnos.

Asimismo es importante enfatizar que ésta técnica depende directamente de la información que se obtenga del entrevistado, factores como lo son la intimidad y complicidad, permiten descubrir poco a poco, aspectos relevantes y trascendentes dentro el tema a investigar, por lo que se realizará en espacios en donde el entrevistado se siente cómodo y seguro con el fin que la conversación fluya sin ningún inconveniente. Es de gran importancia que el entrevistador evite sancionar, restringir o limitar al entrevistado, ya que debido a esto se disminuiría la posibilidad de obtener respuestas sinceras y honestas concuerdo al tema a investigar. (Robles, Septiembre - Diciembre, 2011, p. 4) 
Unos de los primeros pasos para realizar una entrevista a profundidad es el tener claro las personas a las cuales se le pedirá ser parte de esta investigación (entrevistados), además de esto se debe tener en cuenta aspectos básicos como lo son la edad, sexo, estado civil, nivel de estudio, en particular para esta investigación se buscará conocer cuál enfoque de psicología (clínico u organizacional) la persona a entrevistar eligió como vocación dentro del pregrado y campo de acción de la psicología.

Luego el entrevistador debe estructurar la entrevista con el fin de que esta no sea muy pesada para el entrevistado, antes de comenzar es necesario dar a conocer el propósito de la entrevista, darles a conocer que todo lo que digan será analizado con atención y cuidado, atendiendo en todo momento dado en la entrevista y aquello discutido será confidencial los datos del entrevistado. (Robles, Septiembre - Diciembre, 2011, p. 5)

Las entrevistas en profundidad son técnicas cualitativas de investigación que se estructuran a partir de objetivos concretos, por lo que es complicado determinar un número mínimo o máximo de entrevistados, pues la finalidad que tiene esta técnica no obedece a una representación estadística, sino que este consiste en el estudio minucioso de la información que se obtenga con las conversaciones con los entrevistados. En un primer momento se realizará una pequeña entrevista con el fin de que esta sea concisa con la conversación que se llevará con el entrevistado, se le planteará al entrevistado que se harán unas pocas preguntas pero sí la conversación nos lleva se realizará otra pregunta, espontánea, con relación al tema a tratar en esta investigación. En una segunda parte se realizará la transcripción de la entrevista, la cual se convertirá en anexos $^{10}$ del trabajo.

Es recomendable comenzar la entrevista de una forma relajada, con preguntas abiertas, evitando que el entrevistado conteste monosílabamente por medio de afirmaciones o negaciones simples ( $\mathrm{si}$ o no), el fin de las respuestas es que el entrevistado posea la libertad de expresarse como este desee, sin sentirse juzgado, con el fin de que este se sienta lo suficientemente a gusto para enunciar situaciones, experiencias vividas que este crea que

\footnotetext{
${ }^{10}$ Los anexos constituyen una sección adicional a la organización del trabajo de investigación. Su finalidad es proporcional información extra acerca del tema de estudio. Es decir, es aquel material que sirve como complemento al trabajo, estos pueden ser artículos, estudios estadísticos, gráficos, fotografías, mapas entre otros. En este caso los anexos serán las transcripciones de las entrevistas, sin el nombre, edad, estado civil etc., del entrevistado. Estas transcripciones y consentimiento informado será entregado en cuanto este sea pertinente.
} 
son concuerdas con la conversación que se lleva está llevando a cabo. (Robles, Septiembre - Diciembre, 2011, pp. 5 - 6)

Las preguntas aplicadas para esta investigación son las siguientes:

1. ¿Qué lo inspiró a formarse como psicólogo? En el momento que se plantearon las diferentes ramas de la psicología, ¿cuál escogió y por qué?

2. ¿Qué lo motivó a escoger el énfasis en el pregrado? ¿Qué percepción tiene de esta?

3. ¿Cómo fue su experiencia de práctica? ¿Dónde la realizó? ¿Ésta fue determinante posteriormente para decidir su futuro en el ámbito laboral?

4. ¿Tiene alguna razón en específico por la cual decidió tomar el camino del psicólogo organizacional ${ }^{11}$

¿Tiene alguna razón en específico por la cual decidió tomar el camino del psicólogo clínico?

5. Qué lo motiva del campo de acción de dicho énfasis.

6. ¿Se plantearía en un futuro trabajar como psicólogo clínico, en un consultorio, realizando procesos clínicos?

En caso de que la persona posea el énfasis clínico, ¿se plantearía en un futuro trabajar en una organización, trabajar en gestión humana, realizando procesos de selección?

Como última fase de la entrevista a profundización es indispensable contar con todos los recursos posibles para recolectar los datos, las grabaciones, siendo estas en audio o en vídeo, éstas grabaciones son de gran utilidad ya que por medio de estas se realiza transcripciones detalladas, que permiten realizar un análisis más descriptivo en la presentación de resultados de dicha investigación, por medio de estas grabaciones se puede escuchar, el tono, las modulaciones, acentos y frases que el entrevistado utilice a lo largo de la conversación. Para utilizar este medio, es importante llegar a un acuerdo ${ }^{12}$ (Rincón Perferetti) previo con el entrevistado, en donde, este tiene la libertad de aceptar o rechazar

\footnotetext{
${ }^{11}$ Esta pregunta se realizará sí la persona posee el énfasis en gestión humana.

12 Este acuerdo es mayormente conocido como el Consentimiento Informado, este es la autorización que hace una persona con plenas facultades físicas y mentales para que se realice un tratamiento o procedimiento por parte de profesionales. Para funciones de una investigación el consentimiento informado se realiza cuando se hablará de datos íntimos y confidenciales por lo que se realiza un acuerdo con el entrevistado en que estos datos personales no serán públicos.
} 
(a ser grabados). Al iniciar la grabación es imprescindible registrar la ubicación en la cual se está llevando a cabo la cita, la hora y el día.

Para la realización del análisis de las entrevistas es importante realizar anotaciones continuas, tanto de la comunicación del entrevistado, tanto verbal como no verbal, la presencia, la postura, la forma de expresarse, de moverse etc..., de igual manera se debe tener en cuenta las repeticiones que haga, omisiones, titubeos, particularidades del entrevistado que sean relevantes para anotar en el análisis. (Robles, Septiembre Diciembre, 2011, p. 7).

\section{Recolección de datos y análisis de resultados}

Para fines de esta investigación se realizaron entrevistas a profundidad a siete personas diferentes durante un período de tiempo, en donde se realizaron las preguntas expuestas en la metodología, además de esto se tuvo en cuenta la observación de dichas personas durante la realización de las entrevistas. La observación es una técnica útil para el analista en su proceso de investigación, ésta consiste en observar a las personas mientras se efectúa su trabajo, en este caso, la entrevista. Es el medio preferido por los investigadores sociales ya que es una herramienta importante en los procesos de introspección ${ }^{13}$ (Mora, 2007) y extrospección $^{14}$ (s.f. Anónimo); el acto de observar y percibir se constituyen como uno de los principales vehículos del conocimiento humano (Cerda, 1993, p. 237), el acto de observar implica el mirar con un nivel de atención una actividad o fenómeno, es decir, que el entrevistador debe concentrar toda su capacidad sensitiva en el entrevistado, siendo ésta la forma en cómo responde las preguntas, la reacción que provoca la pregunta, movimiento de sus manos, postura en la cual se encuentra entre otros. Por medio del lenguaje corporal ${ }^{15}$ (Sanchidrián Pose, 2013, p. 10) es posible predecir sí el sujeto muestra alguna forma de

\footnotetext{
13 La introspección es la observación que el individuo hace de su propio mundo interior, como sus cogniciones, emociones, motivaciones y conductas. Según Rosenthal (2009), la introspección es el proceso a través el cual adquirimos un tipo de conciencia que se encuentra atenta a nuestros procesos y contenidos mentales.

14 La extrospección, a diferencia de la introspección, es la observación de los fenómenos psíquicos ocurridos en otras personas, éstos no sólo deben ser observados, pero también comprenderlos y explicarlos.

15 La expresión corporal es el lenguaje del cuerpo, natural e inmediato y propio de él. Para Le Boulch, la expresión corporal son las reacciones emocionales y efectivas profundas, ya sean estas conscientes o inconscientes en forma de traducción.
} 
ansiedad, incomodidad u, en una forma más positiva, sí muestra más interés en la pregunta en particular qué las otras.

A lo largo del semestre se utilizó esta técnica en diferentes clases tanto del pregrado cómo de las materias del énfasis, durante una de ellas el profesor pregunta a su clase "¿qué nos motiva? ${ }^{16 "}$ específicamente dentro de un ambiente laboral, a la cual, la clase (compuesta de diversas carreras qué comparten el énfasis de gestión humana), contesta variadas respuestas como: logro, reconocimiento, flexibilidad, desarrollo, crecimiento, ambiente laboral, beneficios, buen jefe y posibilidad de formación, por lo que, este conjunto de individuos le asigna mayor prioridad a aquellos trabajos que les enriquezca en beneficios personales cómo lo son el logro, reconocimiento tanto entre sus colegas cómo de sus superiores, un trabajo que les posibilite una mayor formación, éste puede entenderse cómo el trabajo en equipo, la posibilidad de ascender dentro de la empresa, el posible beneficio de estudio que la propia empresa contenga entre sus beneficios (salario emocional ${ }^{17}$ ) (Fundació Factor Humà), por otra parte, éstos estudiantes de igual manera valoran el clima laboral ${ }^{18}$ de la empresa, el clima laboral se encuentra relacionado con la motivación en el lugar de trabajo ya que éste afecta directamente con la satisfacción reflejados en los trabajadores pues al verse involucrados dentro de un clima laboral favorable se tiende a responder de una mejor manera a los estímulos y se busca, mutuamente, lograr e cumplimiento de los objetivos impuestos por la organización con el objetivo de alcanzar con mayor facilidad la realización de las metas. (García Govea, Escalante Domínguez, \& Quiroga San Agustín, 2012)

Por otro lado, en una clase de pregrado $^{19}$, se realiza un conteo propuesto por la profesor con el fin de conocer el número de estudiantes pertenecientes a los diferentes énfasis, con el fin de la investigación, se tomó sólo en cuenta el número de estudiantes tanto del énfasis

\footnotetext{
${ }^{16}$ Clase subsistema de compensación del profesor Carlos Mario Betancur, realizada los lunes de 9am hasta el mediodía del semestre $2018-2$.

17 El salario emocional es el conjunto de retribuciones no monetarias que el trabajador recibe de su organización y que complementan el sueldo tradicional, tratándose de fórmulas creativas que buscan suplir las necesidades de las personas en la actualidad.

18 El clima laboral consiste en un conjunto de características que rodea a los empleados en el medio ambiente organizacional, éste ambiente causa una diferencia significativa de una empresa a otra ya que demuestra los comportamientos mismos de la organización.

${ }^{19}$ Clase de seminario pos-práctica taller grupal, realizada por el profesor Juan Diego Tobón Lotero, los jueves de 6am a 9am del semestre $2018-2$.
} 
clínico como del énfasis organizacional, los estudiantes pertenecientes al primero fueron unos 24 estudiantes de 34 en total (75\% - 80 \%), y aproximadamente unos 10 estudiantes de $34(10 \%)$ en total pertenecientes del énfasis de gestión humana. Unos meses más tarde en esta misma clase, se realizó un panel de preguntas acerca de la psicología y las organizaciones, el profesor pregunta a los estudiantes presentes cuantos habían tenido una experiencia organizacional en la práctica realizada antes de comenzar el panel de preguntas, en dicha clase se encontraban 11 estudiantes presentes, de los cuales 9 tuvieron experiencia en el área de gestión humana. Es decir, que según la observación realizada a este grupo de estudiantes, su gran mayoría realizaron una práctica en el área organizacional. Relacionando esta observación con la anterior, el énfasis clínico prevalecía como el más constante entre los estudiantes presentes en esta clase, al tomar en cuenta esto, se puede decir que la gran mayoría de los estudiantes próximos a graduar realizaron prácticas organizacionales a pesar de tener énfasis clínico.

En las entrevistas que se llevaron a cabo se halló que la motivación para formarse en psicología o carreras afines, partió desde una edad temprana de la vida que se tuvo contacto con esta misma, o al descubrir las aptitudes para estudiar carreras enfocadas en el área de la salud, destacado así habilidades como el trato con los demás (es decir la empatía e interacción con las demás personas), la ayuda al desarrollo individual (no solamente orientado hacia las demás personas, sino también hacia sí mismos), admiración por la vocación expuesta por personas sujetas a ésta área laboral, el contacto que se tiene con los otros, el deseo de ayudar a las demás personas ${ }^{20}$ etc.... Puntualmente se observó que algunos participantes de la investigación decidieron embarcarse en la medicina antes que aplicar a la psicología. En una instancia, una entrevistada afirma que el hecho de no pasar a esta carrera fue "por razones del destino, quién sabe...", pero también habla que dentro de su vida personal siempre se había encontrado en el ámbito de la psicología y el trabajo social, gracias a que su madre realizaba trabajos con una fundación, por lo que se decide a estudiar psicología ya que ésta "me podía dar herramientas y me podía ayudar en el deseo que yo quería, que era enfocarme en clínica”. Por otro lado, otra persona señala que esta

\footnotetext{
${ }^{20}$ Se entiende por deseo de ayudar a las demás personas como aquella aptitud de servicio la cual la persona se siente en capacidad de ayudarle al otro con sus problemas, a crecer tanto personal como profesionalmente, etc.
} 
motivación ocurrió cuando asistió a un proceso clínico y se sintió identificada con el rol que realizaba la terapeuta dentro de la sociedad, explicando que los "miedos obstaculizan el desarrollo individual, la obtención de logros y la felicidad de las personas, quise estudiar psicología para ayudarle a las personas a enfrentarlos y que fueran más felices”. En otra instancia otro entrevistado afirma que su elección se basó en que la psicología le brindaba una posibilidad para desempeñarse en una profesión que se dedicaba al contacto con lo humano, y que éste va más allá de lo tangible y que de algún modo podría ayudar a la salud mental de la sociedad. A diferencia de estas motivaciones expuestas, una entrevistada asegura que "esperaba salir del colegio sólo para estudiar psicología" debido a que siempre ha querido desempeñarse en ese campo. Se plantea la psicología como aquel instrumento que ayuda a los demás en el desarrollo individual, obtención de logros y la felicidad, el saber el por qué las personas se comportan de cierta manera e ir más allá de esta razón, además que se sienten aptos para realizar estas funciones con el fin de ayudar a la sociedad.

En un sentido más particular, un entrevistado asegura que su motivación para estudiar psicología no fue el deseo de ayudar a las demás personas con sus problemas, sino que esta surgió por su postura personal y su afinidad por la antropología, filosofía y en cierta manera el poder realizar clínica en el ámbito de la salud, replantea la primera pregunta ${ }^{21}$ en un sentido más presente, por lo que en la actualidad afirma que al ejercer esta carrera puede formar una estructura orgánica agregando la antropología, sociología y la filosofía a su qué hacer "enriqueciéndola y nutriéndola desde su esencia". Se concluye que lo que lo motiva de la psicología es que ésta es dinámica y que con ella puede incorporar diferentes formas para aplicarla en su qué hacer profesional, siendo esta en procesos clínicos o en procesos de selección en una organización.

En cuanto a la escogencia del énfasis en su vida académica se observó que los motivos que atraen a las personas a escoger determinado énfasis son variados, por ejemplo, uno de los entrevistados argumenta que su elección fue basada en la idea en que a través de dicha elección se puede llevar a humanizar las organizaciones, buscando siempre potencializar el ser de cada trabajador, manifestado que por medio de este cargo en la organización se debe

${ }^{21}$ ¿Qué lo inspiró a formarse como psicólogo? En el momento que se plantearon las diferentes ramas de la psicología, ¿cuál escogió y por qué? 
entender al ser como sujeto y no como "objeto de trabajo", es decir, una máquina que solamente trabaja y ya, se busca entender su esencia dentro de la organización. Se es motivación también que este se muestra como un reto dentro de la aplicación de la psicología, por medio del entendimiento del otro y la posibilidad de poseer un trabajo dinámico y retador. No obstante se afirma que la psicología clínica no se puede dejar a un lado, debido a que esta es el "apellido" de lo organizacional, "el anillo al dedo", destacando que es importante la aplicación de la clínica dentro de una organización, ya que con esta se llega a un mejor entendimiento de cómo se relacionan las personas con los demás dentro de en una organización, también se asegura que se debe poseer un “ojo clínico” y que éste se comienza a adquirir por medio de la práctica profesional, sin importar el lugar en donde se realice (tanto en lo clínico como en lo organizacional) se asegura que por medio del ojo clínico se halla una transversalidad en el qué hacer y ayuda en la asertividad en la aplicación de ésta. Se especifica que el énfasis que se escoja le brinda al que la utilice, diferentes posibilidades en su qué hacer, y que este es abierto a diferentes funciones dentro del rol en el que se esté desempeñando, es decir, que aquellas personas que se incursionaron en el ámbito organizacional puede potencializar su ojo clínico para llevar a cabo procesos tanto organizacionales como clínicos dentro de una empresa.

Dentro de las diferentes motivaciones en específico de porqué se estudió el énfasis organizacional, se encontró que las personas encontraban retadoras las funciones que se realizaban dentro de la organización, como desempeñar el rol del mediador dentro de la organización, entre los empleados y los jefes, es decir, entre la alta directiva de la organización y la parte más baja de la pirámide que son los operarios, funcionarios entre otros, es decir, los subordinados, siendo el psicólogo aquel que hace que la comunicación "se dé" y que los conflictos internos se puedan resolver. Del mismo modo la variedad de funciones que puede desempeñar el psicólogo dentro de la organización es una motivación que se es constante dentro de cada entrevistado, y el hecho que es posible la implementación de una mirada clínica y analítica a un mundo que "desde afuera se muestra ajeno a esto y a lo humano. También se halla que la satisfacción por encontrar a la persona ideal para una cargo como otro factor que se encuentra dentro de uno de los entrevistados, además de llevar más reconocimiento a lo que es como tal un psicólogo dentro de una organización, manifestando que este cargo les permite ser la primera puerta de una 
organización y realizar análisis pertinentes para encontrar a aquel sujeto idóneo para un cargo. Uno de los entrevistados argumenta que es esa pasión por el qué hacer, y que en la actualidad se encuentra realizando diferentes talleres y charlas dentro del ámbito organizacional, pero también que puede realizar la clínica desde la aplicación de pruebas proyectivas.

En tanto a las motivaciones para escoger el énfasis clínico, se encuentra que es la libertad en el poder decidir en qué enfoque la persona desea sumergirse en cuanto al ejercicio profesional, y esto es tan revolucionario para el entrevistado ya que "se puede elegir la vida desde su profesión" en dicho énfasis le ofrecían la posibilidad de escoger lo que la persona realmente quería y deseaba enfocarse en cuanto a su ejercicio profesional, sí le gustaba la psicología cognitiva, lo hacía, sí le gustaba la dinámica, el psicoanálisis, la humanista etc... Para otro entrevistado es el hecho que por medio de este énfasis se "puede estructurar la psicología a la persona, el poder volverla más orgánica, es decir, poder recurrir a diferentes ramas de la psicología para realizar tanto procesos clínicos como selección”, la persona afirma que en su vida laboral se le es más fácil ajustar la psicología a la persona, qué ajustar la persona que recurre a procesos clínicos a la psicología, planteando que sí se observa por medio del ojo clínico, se puede llegar a conocer diferentes facetas de la persona, es decir, sí la persona disfruta el desarrollar tareas luego de la consulta, es mejor realizarle un proceso cognitivo, sí este desea explicar y contar historia, es mejor enfocarlo desde la dinámica entre otros. El individuo explica que su elección por el énfasis clínico fue debido al deseo de conocer cada vez más al sujeto, el paciente; cada persona tiene una historia de vida muy particular del resto del mundo, es decir, la historia de vida de una persona aun así viviendo en el mismo lugar que otra, con los mismos papás, hermanos, familiares, compañeros etc., es diferente, por lo que lo motiva a no imponer "su psicología" y buscar la mejor teoría que se ajuste a la persona, para argumentar este discurso, la persona plantea que llevó a su esposa (también psicóloga) donde su psicoanalista y a ella no le gustó debido a que "a ella le gusta que le pongan tareas, y hacerlas y todo y... Si ves que cada persona es un rollo diferente y por ejemplo a mí no me gusta que me pongan tareas, yo no funciono con un psicólogo cognitivo". 
Por medio del discurso de los diferentes entrevistados se llega a la conclusión a que la práctica profesional es un punto crítico en cuanto al futuro del qué hacer cada profesional. Éste es el momento en que la persona tiene la posibilidad de aprender no sólo del trabajo de otros, sino de cómo llevar a cabo el propio trabajo.

Uno de los entrevistados relata que por medio de esta época en su vida aprendió acerca de la auto-determinación, debido a que el jefe no les fijó tareas, es decir, no les propuso un plan de trabajo y para cuándo lo debían realizar, sino que éste dejó que sus, entonces practicantes, realizarán el trabajo en cuanto estos lo creían necesario para alcanzar la meta planteada por el departamento. A partir de este suceso la persona auto-determina sus propios logros dentro de la organización e interioriza el discurso del jefe a largo plazo manifestando que esto lo "catapulta ${ }^{22 "}$ a crear diferentes proyectos. En el presente éste usa su auto-determinación para crear su propia empresa, por lo que le debe mucho de su éxito profesional a su antiguo jefe y a su práctica, asegurando que sigue aprendiendo de su autoresponsabilización de su qué hacer.

Otro entrevistado asegura que la práctica fue determinante en tanto que le "abrió los ojos a lo que no quiero hacer", por medio de esta experiencia conoce un lado del ámbito organizacional en el cual no desea desenvolverse, pero también asegura que aprendió de esta experiencia, tanto para su formación profesional como también para su formación personal. En diferente ocasión otro entrevistado asegura que este momento confirmó su deseo de realizar la psicología organizacional en una empresa, pero también buscará que la empresa le proporcione la posibilidad de realizar asesorías clínicas dentro de la organización, cómo lo hizo en su práctica, realizando grupos focales. Otra propone que esta experiencia "me ayudo a consolidar conocimientos teóricos y además me ratifico mi gusto por el área de Recursos Humanos".

Otro entrevistado que tuvo la posibilidad de realizar tres períodos prácticas aseguró que cuando realizó su tercera y última práctica fue cuando "entonces me di cuenta que no me gustaba estar sentada en un escritorio todo el día, que me gusta más cómo moverme, trabajar en diferentes partes, pero me di cuenta que la organizacional me llenaba, que

\footnotetext{
${ }^{22}$ Se entiende esta expresión como algo que impulsa a la persona y en este caso favorece el desarrollo de su ejercicio profesional.
} 
conocía a diferentes personas y aplicaba la psicología clínica, entonces en ese sentido sí fue determinante", por lo que esta persona se encuentra en una dualidad dentro del ejercicio en recursos humanos, ya que este en cierto modo requiere el estarse estático en un lugar pero éste le ofrece la posibilidad de conocer a nuevas personas y ejercer psicología clínico por medio de la aplicación de pruebas, procesos de selección, asesorías etc...

En un panorama general este periodo de práctica fue determinante dentro de los individuos de esta investigación en cuanto a su elección y el desarrollo de sus fortalezas para su qué hacer profesional en un futuro.

Se encuentran diferentes discursos dentro de la pregunta en cuanto a la posibilidad de desempeñar otro rol dentro de los diferentes ámbitos de la psicología en un futuro diferente al que la persona se plantea en la actualidad, algunas personas plantean que han encontrado la pasión y el gusto de querer ser parte de un proceso, de asumir el rol del psicólogo que ayude a la organización desde sus distintos roles. También otro individuo plantea el no poder hacerlo, debido a la desactualización de conocimientos (en este caso clínicos), habilidades y destrezas en el campo, y por el hecho que su motivación personal frente a lo que se dedica en la actualidad (gestión humana) es muy grande como para dejarlo. Otra persona plantea que el verse en un futuro en un consultorio se le es un futuro "monótono" y que buscaría algo que le llene, en este caso las funciones dentro de la organización, de cierta forma, asegura sí proyectarse realizando procesos clínicos, pero realizando a su vez diferentes actividades, planteando un ejemplo de la cotidianidad de los profesores del pregrado, ya que estos realizan procesos clínicos y a su vez se dedican a la docencia, aclara que dentro de un consultorio se pueden apagar diferentes ramas de la psicología haciendo hincapié en la rama de la investigación, la cual le parece fundamental ya que ésta área también le posibilita investigar diferentes temas, ámbitos, ramas de su interés.

Otra persona dentro de la investigación asegura que en un futuro se ve ejerciendo en las dos ramas de la psicología, planteando la posibilidad en un futuro en realizar una especialización con el fin de aumentar sus aprendizajes clínicos ya que disfruta de ver la transformación de las personas, tanto por medio de la terapia como por medio de los procesos de selección, ya que es posible conocer de dónde viene la persona y en qué tiene el potencial de convertirse. 


\title{
Conclusiones
}

\author{
"Vivir con fuerza, conseguir un verdadero sentido \\ y razón de hallar gusto en lo que hacemos es encontrar \\ el más exigente y fructifero de los logros humanos: El Éxito."
}

Concetta de Rissi (Batista Sílva, Hinojosa Cueto, \& Gálvez Espinosa, 2010)

A raíz de esta frase, se hace base lo más intrínseco sobre la motivación y el papel que juega este en la satisfacción que vive el sujeto cuando este alcanza el éxito, posicionando este como aquel sentido que le brinda al sujeto razones para alcanzar los logros que éste se imponga a lo largo de su vida, tanto este halle gusto y placer en alcanzarlo. Es por esto que la vocación le permite a la persona desarrollar sus habilidades, actitudes e intereses con el fin de potenciarlas para alcanzar el éxito y una posición social, éste proceso orienta al individuo a elegir una profesión u ocupación que le llene, que sea movida por su pasión por dicha área del conocimiento. Según Vidales (Pantoja, 1992, p. 18), la vocación no es un acontecimiento innato en el hombre, sino que este es el resultado de un proceso de formación continua que se desarrolla a partir de la cultura, ambiente y el lugar en donde el hombre se desenvuelva, además afirma que no hay un tiempo determinado para la realización de éste por parte del individuo, debido a que todos los momentos son importantes para adquirir dicha vocación. (Pantoja, 1992) Este tiempo se ve reflejado por medio del discurso de uno de los entrevistados cuando este manifiesta que el trabajo organizacional "nunca le ha gustado", pero desde que éste se encuentra inmerso en el trabajo de su empresa de consultoría, le ha empezado a gustar, debido a que éste encuentra grato el hecho de poder trabajar con las personas que trabaja, ser su propio jefe y cumplir un sueño que tenía desde una edad temprana, por lo que encuentra en medio de este ejercicio una vocación por sus funciones ya que éste posee las dos herramientas (tanto la actitud clínica cómo la gestión humana) para realizar un bueno proceso de selección.

Por medio de esta investigación se logró descubrir que las motivaciones que yacen detrás de las decisiones de cada sujeto por formarse como psicólogos fueron, en su gran mayoría, el trato con las demás personas y la posibilidad de desarrollarse dentro de un ámbito clínico dentro del área de la salud. En algunas ocasiones dentro de los discursos de los entrevistados se encontró que la psicología les brindaba aquella herramienta que les 
posibilitaba realizar investigaciones para conocer al ser más allá de lo que éste se plantea a simple vista, conociendo el por qué éste se comporta de cierta manera, cómo influyen diferentes factores en este etc., construyendo por medio de ésta una manera orgánica para integrar las diferentes ramas del conocimiento con el fin de descubrir mejor a los demás, para esto uno de los entrevistados manifiesta que la psicología es este gran conglomerado, un muro gigante, que a menudo los individuos inmersos en este desintegran por su interés por otro énfasis o enfoque, ésta persona argumenta que la psicología debe verse en su totalidad, ya que por medio de todas estas piezas se logra nutrir su esencia y aprender cada vez más; cuando una persona halla gusto y placer en alcanzar sus objetivos, sea el caso particular de integrar la psicología y volverla más orgánica con el fin de mejorar su ejercicio, éste encontrará el éxito por medio de su vocación, ya que este no solamente se siente cómodo en su campo de acción, sino que también siente satisfacción y gratificación por tener la posibilidad de dedicarse a lo que realmente le gusta y le apasiona.

En una instancia un entrevistado relata el mito de la caverna de Platón, relacionándolo con las motivaciones que lo impulsan del énfasis, afirmando que lo motiva su propia ignorancia debido a que esta le permite aprender, descubrir y "de encontrar esa luz que me lleve a entender el comportamiento de muchas cosas, y me motiva mucho porque es el salir de la caverna de.... Platón"; el mito trata de "varios hombres encadenados en una caverna, contra una pared y allí hay un reflejo de una fogata donde hay imágenes de animales... Diferentes cosas, y esa es la realidad de su mundo... y hay uno de esos esclavos que se sale de la caverna, y queda segado con lo que se encuentra por fuera de la caverna, ya que es otro mundo que lo impacta y quiero ser ese hombre que sigue saliendo a la luz y quiere ser parte de esa realidad" 23 , como expresa el mismo entrevistado, la motivación que le brinda el énfasis es que el aprendizaje es continuo, este nunca acaba, siempre habrá investigaciones, teorías, situaciones entre otros por descubrir, lo que hace que su ascensión a los diferentes conocimientos que la vida tiene por ofrecer. Este discurso es corroborado por otro entrevistado, ya que éste establece que su motivación yace en el saber y el conocer analíticamente al ser, ya que de esta manera se tendrá la posibilidad de entenderlo y darle una razón e ir más allá del cómo y del por qué se comporta de la manera que lo hace. Se podría entender que la motivación de estas personas los está conduciendo a un

\footnotetext{
${ }^{23}$ Éste es el relato del mito de Platón según las palabras del entrevistado.
} 
conocimiento y un aprendizaje continuo, por lo que dirigen sus energías a realizar dicho cometido, lo cual es su motivación por tener conocimientos de diferentes índoles, aprender cada día más no solamente teóricamente sino que también de las otras personas, y por medio de esto cada día logran satisfacer este propósito.

En cuanto a las motivaciones para la escogencia del énfasis organizacional se encuentra en los discursos el factor común que es la búsqueda que se propone por parte de las personas en volver las organizaciones más humanas y la búsqueda en potencializar las habilidades del ser de cada trabajador que compone a la organización, ya que, según un entrevistado, muchas veces, las organizaciones dejan de lado lo humano de éstas, y se busca privilegiar otras cosas. De igual forma una de las motivaciones fue el rol que desempeña el psicólogo dentro de una organización, la esencia que posee la Gestión Humana dentro de esta, y el análisis que conlleva la selección de personal, es decir, que la persona que por desempeñar dicho cargo, sea la idónea para ésta. Por otra parte se plantea como decisivo su lugar en diferentes campos de acción, las oportunidades que éste énfasis les plantea para su ejercicio profesional. Se encuentra también implícito ${ }^{24}$ dentro de los discursos de los entrevistados que este énfasis les garantiza un amplio acceso a la labor profesional y que por ende les garantiza una buena remuneración en cuanto a sus labores.

Al interactuar con otras personas se supone un proceso recíproco ubicado dentro de un espacio y tiempo determinado, la motivación hace parte de las vivencias, como lo son las actividades cotidianas que conforman su qué hacer, movilizándolo así hacia una búsqueda de objetivos concretos, relacionado con la interacción que se tiene con el medio ambiente. (Batista Sílva, Hinojosa Cueto, \& Gálvez Espinosa, 2010), a partir de esto una de los entrevistados asegura "cada día me motiva, tocar a las personas con las que tengo contacto, aportarle a sus vidas, ayudarlas a resolver problemas, a mirarse a sí mismas. Aportar en los resultados de la Organización, a través de movimientos en las personas, tener retos cada día..." por lo que la transformación de las personas se encuentra como una de las motivaciones principales que demuestran dicha gratificación en cuanto a su vocación profesional dentro de gestión humana en una empresa, ya que por medio de sus variadas

\footnotetext{
${ }^{24}$ Se encuentra la remuneración como una motivación implícita del ejercicio organizacional, es importante afirmar que ningún entrevistado explicitó este pensamiento por medio de su discurso.
} 
funciones no solamente se puede aportar a los objetivos planteados por la organización, sino que también se puede mover algo dentro del otro, motivándolo a seguir ascendiendo dentro de la organización.

En una oportunidad dentro de la entrevista, la persona relató el proceso que se hizo con una persona que no pasó eventualmente a la organización, pero se le hizo una ayuda para completar su hoja de vida, lo cual el entrevistado, disfrutó de ver cómo la persona pasó de tener ciertas dificultades a llegar a estar estable en la actualidad, describiendo que por medio de la psicología se es posible cambiar la realidad de la otra persona, argumentando “el cómo yo puedo a través de lo que yo hago cambiar la realidad de la otra persona, eso es lo que más me gusta de la psicología y también como hacer una transformación en una persona", por lo que, la persona encuentra una gratificación en su ejercicio, esa satisfacción de ayudar al otro es aquel existir de la motivación viva dentro de ella, ese impulso a seguir trabajando de la manera en que lo hace.

Se halló por medio de las entrevistas que en los primeros semestres del pregrado se tenía ya decidido el camino por el cual la persona se iba a emprender, siendo éste tanto el énfasis clínico cómo el énfasis organizacional, no obstante, se observó qué la práctica profesional incidió en esta decisión, en algunas personas esta experiencia les ayudó a fortalecer dicha vocación por la práctica organizacional afirmando que esta experiencia reforzó su gusto por Recursos Humanos y a la consolidación de teoría previamente aprendida. Otra persona afirma que no fue determinante, ya que su gusto por la organizacional era tan grande que no necesitaba reafirmar su decisión, pero agrega que le gustó tener la perspectiva del ámbito organizacional y vivir aquella experiencia de práctica, asimismo adquirió conocimientos de distinta índole, incorporándolos para tanto su vida personal como la laboral. En otro momento, en donde la persona realizó tres prácticas profesionales, manifestó que aunque de todas afianzó diferentes conocimientos, por medio de su tercera y última práctica, se dio cuenta que el ámbito organizacional la llenaba, que podía conocer a diferentes personas dentro de la organización, y que tenía la posibilidad de aplicar la clínica por medio de pruebas proyectivas, la manera en que podía plantear una entrevista de selección, por lo que de esta manera sí fue determinante en su elección posterior su práctica profesional. 
Asimismo se plantea también que el hecho de realizar la práctica en una organización, no solamente le confirmo a un entrevistado su deseo de convertirse en una psicóloga organizacional, pero también que por medio de ciertos trabajos en este ámbito se es posible realizar clínica, como por ejemplo, realizando grupos focales con diferentes poblaciones de la organización.

Por otro lado un entrevistado asegura que su gusto por la psicología organizacional sólo llegó cuando este se vio inmerso en ésta y cuando creó su propia empresa de consultoría, asegurando que desde que se "metió en este rollo" le ha empezado a gustar, debido a que puede llevar "su" psicología a unirse con diferentes tipos de saberes, llamándolo "una psicología más organizada, orgánica, estructural... La organización me ha incorporado aún más una psicología clínica, y como decía antes el anillo es al dedo como la psicología es a la filosofía, la psicología clínica a la organizacional, pues se complementan, sin la otra es un ave que vuela con una sola ala y queda en el papel del tonto... Y si una persona posee las dos herramientas, la clínica y la organizacional, no ayuda solamente a las empresas con las que trabaje, sino como decía, esencialmente a las personas, no solo hacemos procesos de selección a las personas sino que también hacemos un acompañamiento a que la persona tenga una permanencia en la empresa y limar así pues asperezas, entonces mejorar a la persona en la empresa y hacerla mejor, o si está ya era muy buena, hacerla excelente".

A través del discurso de aquellas personas que participaron en esta investigación se logra evidenciar en cada una de ellas aquel discurso construido a lo largo del pregrado, que es la incorporación de una actitud clínica dentro de la organización, la posibilidad de desempeñarse en diferentes campos en los que se encuentra presente la psicología, siendo estos el organizacional, el jurídico, el deportivo, político, en lo social entre otros, y que éste se encuentra en toda su capacidad de realizar procesos y ser exitoso en este, ya que por medio de este ojo clínico ${ }^{25}$ (Manrique, Lopera, Pérez, Ramírez , \& Henao G, 2015) se logra tener una transversalidad sea en procesos clínicos u organizacionales, y se obtiene una mejor asertividad en la aplicación de esta. Se expresa, a lo largo de todos los discursos, que la clínica es aquella base que sostiene lo organizacional, pues por medio de esta los

\footnotetext{
${ }^{25}$ Se entiende como ojo clínico aquella actitud clínica que se desarrolla a partir del pregrado de psicología, por medio de la escucha, análisis etc. También se puede entender el ojo clínico como aquella actitud de análisis basada en la contrastación entre la teoría y la práctica, este proceso requiere que el individuo entienda, critique, contraste e incorpore, los cuales llevan a una asertividad dentro de la actitud analítica en el investigador.
} 
psicólogos buscan humanizar las empresas, potencializar las habilidades ya existentes en aquellas personas que la conforman, y buscar aquellas maneras que éstas personas se encuentren a gusto dentro de la organización.

En conclusión se entiende la motivación como un proceso que es cambiante, dinámico y el cual es influenciado por la voluntad de cada persona, para este proceso la persona le otorga cierto grado de significancia al proceso como tal, el logro del objetivo y las expectativas que éste tiene en lograr dicha meta planteada por esta misma, siendo ésta voluntad direccionada por medio de los propios sentimientos, aspiraciones, afinidades y valores acordes con las expectativas que el sujeto tiene en cuestión de, en este caso, su elección vocacional. 


\section{Bibliografía}

Aiteco Consultores. (s.f.). aiteco.com. Recuperado el 30 de Abril de 2018, de aiteco.com: https://www.aiteco.com/mcclelland-teoria-necesidades/

Amy Melgarejo, A. M. (2015). Relación entre Inteligencia Emocional y Motivación de logro en Deportistas de Alto Rendimiento. Argentina: Facultad de ciencias jurídicas y sociales, Universidad Argentina de la Empresa.

Anónimo. (s.f.). TÉCNICAS PARA LA RECOLECCIÓN DE DATOS.

Anónimo. (s.f.). Vocación. Recuperado el 30 de Julio de 2018, de http://tesis.uson.mx/digital/tesis/docs/21903/Capitulo3.pdf

Arráez, M., Calles, J., \& Moreno de Tovar, L. (2006). La Hermenéutica: una actividad interpretativa. Sapiens. Revista Universitaria de Investigación, 171-181.

Barberá Heredia, E. (1997). Modelos Explicativos en Psicología de la Motivación. Revista Electrónica de Motivación y Emoción.

Batista Sílva, A., Hinojosa Cueto, I., \& Gálvez Espinosa, M. (2010). Condiciones motivacionales internas y rendimiento académico de residentes venezolanos en Medicina General Integral . Revista Cubana de Medicina General Integral .

Castañeda Lemus, M. (2004). MOTIVOS, EXPECTATIVAS E INTERESES DE LA ELECCIÓN DE LAS CARRERAS DE PSICOLOGÍA CLÍNICA Y PSICOLOGÍA INDUSTRIAL EN ESTUDIANTES DE PRIMER AÑO DE LA UNIVERSIDAD RAFAEL LANDÍVAR. Tesís de Grado, Universidad Rafael Landívar, Guatemala.

Cerda, H. (1993). Capítulo 7: Medios, Instrumentos, Técnicas y Métodos en la Recolección de Datos e Información. En H. Cerda, Los elementos de la investigación (pág. 237). Bogotá: El Buho .

Conasa. (19 de Enero de 2015). Conasa IT Works. Recuperado el 8 de Mayo de 2018, de Conasa IT Works: http://www.conasa.es/blog/elearning-y-motivacion-tecnicas-apartir-de-la-teoria-de-mcclelland/

Cuervo, K. (s.f.). Finanzas Personales. Recuperado el 3 de Septiembre de 2018, de Finanzas $\quad$ Personales: http://www.finanzaspersonales.co/trabajo-yeducacion/articulo/como-funcionan-las-practicas-profesionales/60563

EAFIT. (s.f.). EAFIT. Recuperado el 16 de Agosto de 2018, de EAFIT: http://www.eafit.edu.co/pregrado-psicologia 
EAFIT. (s.f.). eafit.edu.co. Recuperado el 16 de Agosto de 2018, de eafit.edu.co: http://www.eafit.edu.co/58/tiempo/Paginas/1960.aspx

EAFIT. (s.f.). eafit.edu.co. Recuperado el 16 de Agosto de 2018, de eafit.edu.co: http://www.eafit.edu.co/programas-academicos/pregrados/psicologia/acercaprograma/Paginas/generalidades-psicologia.aspx

Federación de Enseñanza de CC. OO. de Andalucía . (2011). LA INTELIGENCIA EMOCIONAL . Revista digital para profesionales de la enseñanza, 5.

Fernando Toro Álvarez, Centro de Investigación e Interventoría en Comportamiento Organizacional. (1998). MOTIVACIÓN PARA EL TRABAJO: DERIVACIÓN DE FACTORES DE SEGUNDO ORDEN A PARTIR DEL TEST MOTIVACIONAL CMT . Revista Interamericana de Psicología Ocupacional, Volumen 17, $N^{\circ} 1,4$ 18.

Figueroba, A. (s.f.). Psicología y Mente. Recuperado el 3 de Mayo de 2018, de Psicología y Mente: https://psicologiaymente.net/psicologia/teoria-motivaciones-davidmcclelland

Fundació Factor Humà. (s.f.). Fundació Factor Humà. Recuperado el 27 de Septiembre de 2018, de Fundació Humà: https://factorhuma.org/attachments_secure/article/8299/salari_emocional_cast.pdf

García Govea, M. E., Escalante Domínguez, M., \& Quiroga San Agustín, Y. (2012). Importancia del clima laboral en los resultados de una empresa y la competitividad. Málaga: Contribuciones a la Economía.

González Cuevas, O. M. (s.f.). El concepto de Universidad. México: Universidad Autonoma Metropolitana Azcapotzalco.

González Serra, D. (2008). Psicología de la Motivación. La Habana: Ciencias Medicas.

Grupo Akal. (08 de Noviembre de 2016). nocierreslosojos.com. Recuperado el 23 de Mayo de 2018, de nocierreslosojos.com: http://www.nocierreslosojos.com/dineromotivacion-herzberg-teoria/

IBERTIC. (s.f.). Entrevistas a profundidad: guía y pautas para su desarrollo.

Infocif. (14 de Julio de 2015). noticias.infocif.es. Recuperado el 8 de Mayo de 2018, de noticias.infocif.es: https://noticias.infocif.es/noticia/como-aplicar-la-teoria-demcclelland-la-organizacion

Maldonado Oñate, R. (2016). El método hermenéutico en la investigación cualitativa. https://www.researchgate.net/publication/301796372: Universidad de Concepción . 
Manrique, H., Lopera, I., Pérez, J., Ramírez , V., \& Henao G, C. M. (2015). Clínica de las organizaciones: una propuesta analítica. Medellín.

Manso Pinto, J. (2002). EL LEGADO DE FREDERICK IRVING HERZBERG . Revista Universidad EAFIT, 79 - 86.

Méndez, A. (2013). euroresidentes.com. Recuperado el 16 de Marzo de 2018, de euroresidentes.com:

https://www.euroresidentes.com/empresa/motivacion/motivacion-segun-autores

Ministerio de Educación Nacional. (s.f.). cna.gov.co. Recuperado el 16 de Agosto de 2018, de cna.gov.co: https://www.cna.gov.co/1741/article-186377.html

Ministerio de Educación Nacional. (s.f.). mineducacion.gov.co. Recuperado el 3 de Septiembre de 2018, de mineducacion.gov.co: https://www.mineducacion.gov.co/1621/article-87727.html

Mora, C. (2007). Introspección: Pasado y Presente. Segunda Época Volumen XXVI N², 59 -60 .

Naranjo Pereira, M. L. (2009). MOTIVACIÓN: PERSPECTIVAS TEÓRICAS Y ALGUNAS CONSIDERACIONES DE SU IMPORTANCIA EN EL ÁMBITO EDUCATIVO. Revista Educación , 153-170.

Navarrete Cazales, Z. (2015). La universidad como espacio de Formación profesional y constructora de identidades. Universidades, 5 - 16.

Navarrete Cazales, Z. (s.f.). La .

Orange, D. M. (2003). El Desconocido que Sufre. Hermenéutica para la Práctica Clínica Cotidiana. 2013: Cuatro Vientos.

Pantoja, C. (1992). En torno al concepto de vocación... Educación y ciencia, 17 - 20 .

Peña Estrada, C. (2015). La motivación laboral como herramienta de gestión en las organizaciones empresariales. . Madrid: Universidad Pontificia Comillas ICAIICAIDE .

Psicología Global. (2 de Mayo de 2012). Psicología Global. Recuperado el 8 de Mayo de 2018, de Psicología Global: http://www.psicologiaglobal.com/?p=317

Real Academia Española. (s.f.). rae.es. Recuperado el 26 de Julio de 2018, de rae.es: http://dle.rae.es/srv/search?m=30\&w=tendencia

Real Academia Española. (s.f.). rae.es. Recuperado el 23 de Julio de 2018, de rae.es: http://dle.rae.es/srv/fetch?id=LnK5Dm7 
Real Academia Española. (s.f.). rae.es. Recuperado el 23 de Julio de 2018, de rae.es: http://dle.rae.es/srv/search?m=30\&w=impulso

Revista Interamericana de Psicología Ocupacional. (1998). Motivación para el trabajo: derivación de factores de segundo orden a partir del test motivacional CMT . Revista Interamericana de Psicología Ocupacional.

Rincón Perferetti, G. H. (s.f.). encolombia.com. Recuperado el 23 de Agosto de 2018, de encolombia.com: https://encolombia.com/medicina/revistas-medicas/heraldomedico/vol-231/heraldo231-cosentimiento/

Robles, B. (Septiembre - Diciembre, 2011). La entrevista en profundidad: una técnica útil dentro del campo antropofísico. Cuicuilco, vol. 18, núm. 52, 39-49.

s.f. Anónimo. (s.f.). Aspectos básicos: ramas y métodos de la psicología.

Sanchidrián Pose, R. (2013). EXPRESIÓN CORPORAL: DESARROLLO DE LA DESINHIBICIÓN A TRAVÉS DEL JUEGO. Valladolid.

Segú, M. (2015). La vocación y el imaginario en la elección de los estudios de trabajo social en la comunidad autónoma del país Vasco (Tesis Doctorado). Donostia, San Sebastián.: Deusto, facultad de Ciencias Sociales y Humanas,.

Utria, O. (2007). LA IMPORTANCIA DEL CONCEPTO DE MOTIVACIÓN EN LA PSICOLOGÍA. Revista Digital de Psicología, 63. 